\title{
Erratum to: Variability of gas composition and flux intensity in natural marine hydrocarbon seeps
}

\author{
Jordan F. Clark • Libe Washburn •
}

Katherine Schwager Emery

Published online: 5 March 2010

(C) Springer-Verlag 2010

Erratum to: Geo-Mar Lett

DOI 10.1007/s00367-009-0167-1

The original version of this article unfortunately contained a mistake. In the "Field Site" section (page 2, column 2, line 9), Eliza Bradley noticed that the methane gas flux was mistakenly converted to $30 \mathrm{~mol} / \mathrm{s}=1.5 \times 10^{-5} \mathrm{Tg} / \mathrm{yr}$. The correct conversion is $30 \mathrm{~mol} / \mathrm{s}=1.5 \times 10^{-2} \mathrm{Tg} / \mathrm{yr}$.

The online version of the original article can be found at http://dx.doi. org/10.1007/s00367-009-0167-1.

J. F. Clark $(\bowtie) \cdot$ K. S. Emery

Department of Earth Science, University of California,

Santa Barbara, CA 93106, USA

e-mail: jfclark@geol.ucsb.edu

L. Washburn · K. S. Emery

Department of Geography, University of California,

Santa Barbara, CA 93106, USA

K. S. Emery

Department of Ecology, Evolution and Marine Biology,

University of California,

Santa Barbara, CA 93106, USA 